\title{
Introduction of Embedded Computing System Course at First Year Level in Engineering Education
}

\author{
Keerti Naregal ${ }^{1}$, Anand Gudnavar ${ }^{2}$ \\ Department of Computer Science and Engineering, KLE DR MSSCET, Belgaum, Karnataka, India ${ }^{1}$ \\ Department of Electronics and Communication Engineering, KLE DR MSSCET, Belgaum, Karnataka, India ${ }^{2}$
}

\begin{abstract}
Exposure to embedded systems is very important for engineering students these days, as almost all branches of engineering make use of embedded computing systems. Exposure to the embedded systems and hands-on learning is usually late in the curriculum if present, and may fail to arouse interest in the students about the subject and related systems. Introduction of Embedded Computing system course at first year level in engineering education helps develop interest in related systems and also help students chose their elective subjects effectively later in the four year engineering course to successfully achieve their intended goals and also give them the edge required to enter the industry with confidence. This paper describes an experience with the usage of embedded development kits at second and third-year levels and proposes the introduction of such a program at first-year level.
\end{abstract}

Keywords: embedded systems, UTLP, hands-on learning, first year BE.

\section{INTRODUCTION}

With the continuous development of the electronics and computing industry various electronic products and devices have emerged in our daily life and in the engineering application fields as well. In order to fulfill the requirements of industry, engineering graduates need to know basics of embedded systems.

Students of Electrical and Electronics, Electronics and Communications, Computer Science Engineering, BioMedical Engineering, Instrumentation technology, Medical Electronics, Telecommunications are introduced to embedded systems as part of curriculum, only during the pre-final year or final year and not always associated with a embedded systems lab. Students of mechanical and related branches do not have a course on embedded systems though robotics and Micro-electromechanical systems (MEMS) are emerging technologies these days. Sensors are widely used in civil engineering applications for measurements of temperature, strain, displacement etc. and students have very little insight in them.

In total almost all branches of engineering make use of embedded systems. An introduction of the embedded systems and their programming at an early level can arouse interest in the students for the related systems and tune them for their future study. Introduction to the embedded system development kit and programming on the kit with a language like $\mathrm{c}$ (which the students learn at the first-year level) can help develop their design and programming skills.

The fact that embedded systems are key components used in many industries (including the automotive, consumer electronics, military/aerospace, office automation, telecommunication, and data-communication industries) and that demands for qualified embedded systems engineers are increasing suggests that students should be exposed to embedded systems concepts earlier on in their education [1].
Teaching embedded systems concepts to students with little or no computing experience is challenging. This paper describes the experiences in the Unified Technology Learning Platform (UTLP ) program carried out at KLE engineering college Belgaum and proposes introduction of semester-long course including hands-on training and some theoretical basics on embedded systems at first year level. Section II describes the programs carried out at Dr. M. S. Sheshgiri College Of Engineering and Technology Belgaum and its outcome. Section III provides details of the Wipro's Unified Technology Learning Platform. Section IV provides details of the proposed course. The conclusions are briefed in Section V.

\section{Programs Carried Out And Its Outcome}

Teaching embedded systems concepts to students who lack background computing knowledge can be challenging. But various hands-on training program feedbacks have shown that [6] students can learn better and find it interesting when courses have substantial hands-on components [1][3]. Courses that have a "handson" nature can provide some fun and excitement in a student's learning experience and ensure that he/she will not easily forget what has been learned [4].

Unified Technology Learning Platform (UTLP) is a program launched by Wipro's Mission10X. Mission10X a Wipro initiative, has partnered with iWave Technologies in the design and development of the Platform which addresses the needs of various engineering disciplines.

Currently as part of the UTLP program at KLE Engineering College, the second, third and final year students of Electrical \& Electronics, Electronics \& Communications, Computer Science, Bio-Medical Engineering and Telecommunications department are trained for a week on using the kit and developing applications. 
A dedicated laboratory is made available to them for developing applications.

The UTLP program has been carried out successfully for three years at the KLE Engineering college Belgaum, starting from the odd semester 2012-13.Three staff underwent training organized by Wipro's Mission 10x "UTLP Practitioner Training Program", at Wipro Technologies Bangalore in Sep 2012. These three staff in turn trained three faculties each from six different departments. These trained eighteen staff trained the students of the pre-final year of their respective departments. The trained students helped their juniors' during the next semester with the usage of the platform by conducting a similar program. The same three faculties, who had undergone the initial training program at Wipro Technologies Bangalore, underwent a second level training called "UTLP Expert Training Program" in Oct 2013. A total of around two hundred students have undergone training on the basic level usage of the platform. The UTLP platform has a lot of features; advanced level trainings are planned to explore these features and are to be executed.

\section{A. Projects Implemented}

With the weeklong training conducted on the usage of the UTLP, students of various departments have been able to develop various simple projects; following are a few of them

1. Glowing LED: Objective was to glow LED in a random fashion. Students were able to write and implement their own random number generator code, as standard library functions cannot be used.

2. Simple calculator: Basic arithmetic operations are carried out. Input is provided using the keypad interface and graphical LCD and operations are decided based on the colors selected on the graphical LCD. The graphical LCD is split up into a matrix of $2 \times 2$, having 4 colors, each depicting a different arithmetic operation.

3. Student Record System: Various peripherals on the UTLP are used and a student record system is developed. Data entry is made through peripherals like keypad and student data are displayed on the character LCD, pass or fail is depicted through colors (green, red) on the graphical LCD. Insertion of data is also done through the graphical LCD.

4. Gaming applications: Games like Tic-tac-toe, snake and ladder have been developed on the graphical LCD. Inputs are provided on graphical LCD and output is also seen on the same.

5. Data compressor: Compression of text data using Huffman coding algorithm.

6. A team of three students from Bio-Medical Engineering department implemented their final year project on the UTLP platform titled "Arrhythmia analysis and classification of ECG using OMAP". The objective of the project was to correctly identify and classify the given ECG signal. The data for the ECG signal was obtained from the MIT-BIH database. This ECG was then displayed on the GLCD of the UTLP, which was quite challenging. An algorithm was used to classify this
ECG based on the R-to-R peak and the classification message was displayed on the CLCD. The students involved in the project, enjoyed exploring the features of the UTLP.

The implementation of the projects describes the success of the program.

Written feedback was collected from students at the end of each training program. Most of the students mentioned that they enjoyed the program and it was fun learning the things. Many students suggested that they would like to have a longer duration program

With the success of the projects implemented and based on the feedback collected from the students, the proposal of the semester-long course on embedded system during the first year BE is made.

\section{III.DETAILS OF THE UNIFIED TECHNOLOGY LEARNING Platform}

UTLP is an ardent facilitator for aiding engineers gain hands-on, learn and understand complex and advance technologies simply. Besides, UTLP also concentrates on making students and freshmen industry ready as it gives them the experience of working in real time. UTLP embraces modern technologies to bridge the gap between academia and industry. It increases individual learning towards subjects and supports and motivates students towards building and integrating concepts keeping in mind organizational practices. UTLP board is shown in Fig 1.

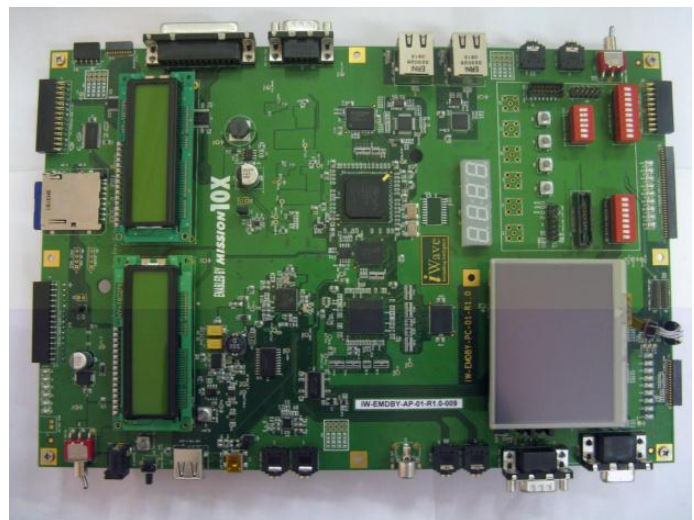

Fig 1. The UTLP Board

There are three 3 major components to the UTLP:

- Cutting edge Hardware Technology: A hardware which combines integrated and custom logic, comes with a Multimedia TI OMAP 3530@600 MHz processor; a built-in DSP core and Xilinx Spartan 6 FPGA. This support interfaces required input devices, Display devices and connectivity. This makes it work independently as a standalone box as well. With the use of FPGA, one could develop products with customer features on this.

- Open Source Software: While presently equipped with the UBOOT and Linux Operating System, with X11 graphics, other embedded operating system like WinCE and android can also be supported. A basic API library is also provided from which user can easily develop their own application with minimal effort. This will allow users, to implement their custom algorithms. 
- Learning Assets: This provides faculty members with enablers to take students to higher levels of learning and includes training materials, resource guides, assessment framework including video tutorials. The contents that come on the DVD provided with UTLP, include user manuals, which contain detailed function-level details about the software and hardware details to the pin/interface level. The DVD also contains simple experiments around most of the interfaces available on the hardware with source code. Key components to ensure that the solution is learner-friendly include a Faculty Resource Guide(FRG) which contains detailed explanation of how the experiments could be conducted in the UTLP lab and an Application Programming Interface (API) which helps students develop higher level applications with ease.

\section{IV.Proposed COURSE}

"Embedded systems" is a subject concerned to all branches, so a proposal is made for the introduction of the course at the first-year level. A semester-long course, after or along with c programming course (which the students already have at a first year level) focused on lab session than on the theoretical aspects of the subject can arouse interest in the embedded products related to their branches.

\section{A. Course Duration}

A semester-long course with four hours per week, comprising of three hours of practical session and one hour of theory session or as per university calendar.

The course spans for ten weeks, thus making a total of forty hours.

Students can make use of UTLP or any other similar platform.

\section{B. $\quad$ Course Content}

The following are the topics for the proposed course:

- Introduction to the operating system and Integrated Development Environment used along with the embedded system development platform.

- Introduction and basic study of the processor and other hardware on the embedded system development platform used.

- Introduction to the peripherals on the embedded system development platform and their interfacing.

- Usage of the API for writing programs for the embedded system development platform.

- Introduction to the embedded products specific to the engineering branch, for example, the pacemaker for BioMedical Engineering.

\section{Assessment Of The Course}

The course is devised in such a way that more emphasis is given to the practical sessions. The assessment, therefore, would take into consideration the lab assignments and the mini-projects implemented.

\section{Conclusion}

In this paper, we describe the importance of embedded systems in various engineering streams. Based on the success of the UTLP program conducted at our college at second, third and fourth year level and the feedback collected from the students, a proposal for an embedded system course at first year level is made. The course highlights on hands-on learning. With the introduction of embedded system course at a first-year level, it is believed that the students can choose and focus their future course subjects, according to their interest, requirements, and abilities.

\section{ACKNOWLEDGMENT}

The authors thank Management and Principal KLE Dr. M. S. Sheshgiri College of Engineering and Technology for having set up the Mission 10x Technology Learning Center and making the UTLP available to the students of KLE Engineering College. The authors would like to thank Wipro Mission 10x for having introduced UTLP and for their constant support to the programs carried out at our college. Special thanks to Prof S. B. Kulkarni, Head Electronics and Communication department for making the UTLP program at KLE Engineering College a great success. The authors also thank all the Heads of Departments of the various departments of the KLE Engineering College for providing their support

\section{REFERENCES}

[1] B. Benson, A. Arfaee, Choon Kim, R. Kastner, and R.K. Gupta. Integrating embedded computing systems into high school and early undergraduate education. IEEE Transactions on Education, 54:197-202, 2011

[2] F. F. Vahid and T. Givargis. Timing is everything embedded systems demand early teaching of structured time-oriented programming. In Proc. Workshop Embedded Syst. Educ., 2008.

[3] Chien-Ming Wu Chun-Ming Huang Kai-Chao Yang, Yu-Tsang Chang and Chin-Long Wey. Universal learning system for embedded system education and promotion. International Journal of Advanced Computer Science and Applications, 4:14-22, 2013.

[4] Tulika Mitra. Challenges in designing embedded systems courses. In Workshop on Embedded Systems Education in conjunction with EMSOFT, 2006.

[5] W. Wolf. Rethinking embedded microprocessor education. In Proc. Amer. Soc. Eng. Educ. Annu. Conf. Expos., 2001

[6] Kai-Chao Yang, Yu-Tsang Chang, Chien-Ming Wu, Chun-Ming Huang, and Hua-Hsin Luo. Application-oriented teaching of embedded systems. In 2011 IEEE International Conference on Microelectronic Systems Education (MSE), 2011 